\title{
A moderated-mediation model of fear of illness and subjective psychological well-being during COVID-19 pandemic
}

\section{Sarita Sood ( $\nabla$ sarita.sood@yahoo.com )}

University of Jammu https://orcid.org/0000-0002-6108-1313

\section{Ananya Sharma}

University of Jammu

\section{Research Article}

Keywords: resilience, pandemic, mental health, media, adversity

Posted Date: December 3rd, 2020

DOI: https://doi.org/10.21203/rs.3.rs-100641/v2

License: () (7) This work is licensed under a Creative Commons Attribution 4.0 International License. Read Full License 


\section{Abstract}

A sudden outbreak of diseases poses a serious threat to mental health. Relying on strengths might mitigate negative mental health outcomes and promote positive mental health. Prior research suggests a potential moderated mediation effect between fear of illness and subjective psychological well-being. Based on the Complete State Model and the Competence-Based Model of mental health, this study examined the relationship between fear of illness and subjective psychological well-being through perceived distress moderated by resilience in the context of COVID-19 pandemic. A cross-sectional survey using questionnaires was employed. Data were collected online from 384 participants ( 270 females and 114 males, age range= 15 to 29 years). The participants had indirect exposure to COVID-19 through information from the media. Results demonstrated that fear of illness significantly predicts subjective psychological well-being both directly and indirectly. In addition, the moderated mediation effect of resilience was confirmed. Resilience moderated the indirect effect between fear of illness and subjective psychological well-being through perceived distress. The magnitude of the indirect effect was contingent on resilience. Further, the effect of perceived distress on subjective psychological well-being is weakened as the level of resilience increases. This study contributes theoretically to a better understanding of the salutogenic effect of resilience on positive mental health during a pandemic. Based on the findings, implications and future directions are discussed.

\section{Introduction}

The current pandemic of novel coronavirus disease (COVID-19) is spreading and affecting people exponentially day after day. Novel diseases are traumatic as they give a sense of uncertainty and act as a threat to life which triggers fear of illness (Vahedian-Azimi, 2020). Extant literature reveals negative mental health outcomes are sequelae of exposure to traumatic events (Pine et al., 2005; Su \& Chen, 2015). During the locked-down period, there was greater indirect exposure to the information related to infection. Otu et al. (2020) acknowledged that prolonged exposure to the information on COVID-19 has the potential to impact mental well-being. Nevertheless, continuous exposure to COVID-19 related information has acted as a major stressor thus developing a fear of contracting an infection (Lin, 2020).

Fear of illness during current pandemic is the fear of contracting COVID-19 infection. Fears pose a serious threat to our well-being, hence, cannot be left unattended (Pappas et al., 2009). Undeniably, the fear of developing illness during pandemics may translate into a range of mental health outcomes.

During a pandemic, it is atypical to exhibit symptoms of negative mental health (Boyraz \& Legros, 2020). In the grim situation of COVID-19, psychological distress might increase whereas well-being might decrease (Rashid \& McGrath, 2020). Hence, during pandemics along with mitigating the negative mental health, it has become necessary to build on the strengths to enhance positive mental health. It is a vociferous call of the researchers (e.g. Chen et al., 2020; Mamun \& Griffiths, 2020) to identify preventive factors to curb negative mental health repercussions of the pandemic, which is still untapped.

A large and sufficient amount of empirical evidence demonstrates that the COVID-19 pandemic has lowered subjective well-being (e.g. Ahuja et al., 2020; Blasco-Belled et al., 2020; Satici et al., 2020; Yildirim \& Arslan, 
2020; Zacher \& Rudolph, 2020). So far, while the greater emphasis has been given to the pathogenic aspect, very little attention has been paid to the positive mental health and salutogenic factors. Moreover, studies assessing both psychological distress and psychological well-being in the same sample are scant (e.g., Jiang, 2020; Paredes et al., 2020; Tecson et al., 2019). Nevertheless, the aforementioned studies revealing an inverse relationship between psychological well-being and psychological distress were carried out in different contexts, other than pandemics or outbreak of diseases. Hence, the findings though could set the ground for the need for measurement of both psychological well-being and psychological distress in the same sample but we fail to ascertain its relevance for pandemic-like situations. For this reason, the present study intended to fill these gaps and assess the indispensable role of resilience in enhancing subjective psychological well-being even when symptoms of psychological distress are evident. We propose that the relationship between fear of illness and subjective psychological well-being is moderated by resilience and mediated through perceived distress. The purpose of the present study is to understand the conditional indirect effect of fear of illness on subjective psychological well-being through perceived distress and to examine how salutogen resilience buffers this relationship (moderated-mediation model). In line with the Strength/Competence-based Model of mental health, amplification of resilience is expected to mitigate the effect of perceived distress and increase one's subjective psychological well-being. The exploration of these linkages will help in understanding the relevance of each variable in designing protective and preventive interventions to combat COVID-19 and similar pandemics.

The contribution of this study lies in testing the applicability of Competence-based Model of mental health in the context of COVID-19 pandemic. Further, it clearly spells out the requirement of focusing on maximizing positive mental health through the adoption of a preventive stance. It also provides evidence on the salutogenic effect of resilience thereby diminishing perceived distress and augmenting subjective psychological well-being which in turn is affected by the fear of illness.

In the following sections, we review the existing literature on fear of illness, subjective psychological wellbeing, perceived distress, and resilience. We then describe the method of the study and findings. We conclude by discussing the implications of our work and offering suggestions for future research.

\section{Theoretical Background and Hypotheses Development}

Positive psychology holds that negative and positive outcomes co-occur. The presence of a high level of psychological well-being and low level of mental illness as important components of mental health which co-exist (Diener \& Lucas 2000). Winefield et al. (2012) opine that perceived distress and psychological wellbeing are not unidimensional and need to be measured separately. Consequently, it requires an assessment of both components of mental health so as to promote positive and prevent negative mental health outcomes. Psychological distress and subjective psychological well-being are indicators of negative and positive mental health respectively (Kane, 2019). In this study self-perceived subjective aspects of both negative and positive mental health are studied.

\section{Strength/Competence-based Model of Mental Health}


In adverse life situations, it is important to face challenges and mitigate negative outcomes. During a crisis, the presence of negative mental health or outcomes cannot be ignored, thus requiring repair of damage to complement negative by building strengths (Luthans \& Church, 2002). Due to this reason, attention should be paid to positive mental health for it is relevant in the COVID-19 pandemic. Positive mental health is evident through subjective psychological well-being (Suldo \& Shaffer, 2008). The theoretical grounding for building on the inherent capacities of an individual to reduce suffering is provided by the Strength/Competence-based Model of mental health (Southwick et al., 2014). Strengths act as salutogens and help in managing the demands of negative life events (Rashid \& McGrath, 2020). Possibly, resilience acts as a salutogen and maximizes positive outcomes. Resilience is an individual's capacity to adapt or recover from threatening or destructive forces (Masten, 2001; Smith et al., 2008). Färber and Rosendahl (2018) affirmed that resilience can enhance positive mental health as it helps in adaptation to the stressors. Moreover, resilience acts as a buffer to mental health problems. In line with the strength based approach, individuals with a higher level of resilience might experience better subjective psychological well-being irrespective of the extent of the perceived psychological distress (Rashid \& Seligman, 2018).

\section{Fear of Illness as Predictor of Perceived Distress and Subjective psychological Well-being}

Huppert (2009) proposed that the same factors might act as precursors for both positive and negative mental health. There is loads of evidence to suggest that fear of illness predicts negative and positive mental health. More recently, in the context of the COVID-19 pandemic, the positive relationship between fear of illness and psychological distress has become apparent (Ahorsu et al., 2020; Harper et al., 2020; Newby et al., 2020; Parlapani et al., 2020; Satici et al., 2020). Further, Shigemura et al. (2020) found an association between heightened fear of illness and the potential development of mental health disorders even among healthy people during the current pandemic. It could be said that due to increased fear of illness there is potential to see deterioration in mental health, predisposing the general population to develop symptoms of psychological distress. The fear of illness can also be a challenge to maintain positive mental health during adversity. In a study conducted on 1772 Turkish adults during the COVID-19 pandemic, Satici et al. (2020) not only reported a significant positive relationship between fear of COVID-19 and indicators of psychological distress namely depression, anxiety, and stress but also found that the fear of COVID-19 negatively predicted well-being. Empirical findings show that with the fear of COVID-19, well-being was inversely related (Ahuja et al., 2020; Amin, 2020; Hsing et al., 2020). Serafini et al. (2020) confirmed that fear of illness deteriorates subjective psychological well-being. Thus, it appears that fear of illness is a precursor of positive and negative mental health. Based on the empirical evidence and theoretical support given above, the following hypotheses have been framed:

H1: Fear of illness relates negatively to subjective psychological well-being.

H2: Fear of illness relates positively to perceived psychological distress. 


\section{Fear of Illness and Subjective Psychological Well-being: The Mediating Role of Perceived Distress}

Negative reactive responses and thoughts spiral into and characterize the COVID-19 crisis. Several researchers have reported negative mental health during the current pandemic (Abramson, 2020; Kumar \& Nayar, 2020). The findings of these studies provide an insight that indirect exposure to traumatic life situations develops signs of psychological distress even in the general population (Hsing et al., 2020; Pine et al., 2005). Hence, indirect exposure to COVID-19 related information through media increases perceived distress which in turn might affect subjective psychological well-being. The relationship between perceived distress and psychological well-being has been supported by previous researchers. Jiang (2020); Meng and D'Arcy (2016); Mankiewicz et al. (2013); Tecson et al. (2019) have provided empirical evidence that perceived psychological distress is significantly and inversely related to psychological well-being. Therefore, the aforementioned studies show that psychological distress has a negative impact on subjective psychological well-being.

Previous empirical studies support the mediating role of psychological distress between fear of illness and subjective psychological well-being. As emerged by the recent literature, depression, anxiety, and stress which are the symptoms of negative mental health, play a mediating role in the relationship between the fear of COVID-19 and life satisfaction (Satici et al., 2020). In addition, the fear of COVID-19 was shown to increase negative mental health outcomes and to decrease positive mental health. Based on these findings the following hypothesis has been framed:

H3: Perceived distress mediates the relationship between fear of illness and subjective psychological wellbeing.

\section{Perceived Distress and Subjective Psychological Well-being: The Moderating Role of Resilience}

According to Huppert (2009) psychological well-being tends to decline in case an individual remains in a negative state for a long period of time. Hence, understanding the pathways to enhance well-being becomes important especially when positive and negative mental health share the same drivers. Resilience has been researched extensively in the context of stressful and adverse life situations (Polizzi et al., 2020). As per Bakioğlu et al. (2020) during COVID-19, the protection of mental health and enhancement of psychological resilience is of prime importance. Researchers propose an exploration of the moderating role of resilience between adverse conditions and positive mental health (Min et al., 2015). Researchers hold that resilience gets activated in adversity (Bonanno et al., 2008; Southwick et al., 2014) and facilitates coping (Connor \& Davidson, 2003). Further, Polizzi et al. (2020) argued that people endowed with resilience inevitably are able to survive and overcome the fear of being pulverized and persevere. Hence, resilience is associated with both positive and negative mental health (Shapero et al., 2019; Srivastava, 2011). Resilience has revealed to result in lowering symptoms of negative mental health (Tecson et al., 2019). Further, researches indicated that resilience enhances positive mental health (Cuhadar et al., 2016; Vieselmeyer et al., 2017) in particular 
subjective well-being (Satici, 2016; Tecson et al., 2019; Yildirim \& Arslan, 2020) and it acts as a protective factor (Serafini, 2020).

Presence of resilience during adverse life situations acts as a salutogen and helps in coping with the stressors thus diminishing negative consequences so that positive mental health improves. It could be said that, during pandemics activation of resilience, is the conditional factor that affects the mediated relationship between fear of illness and subjective psychological well-being. In the presence of high resilience, the effect of mediator perceived distress gets weaker between the relationship of fear of illness and subjective psychological well-being. Therefore, resilience may influence the mediated relation between perceived distress and subjective psychological well-being. Hence, we propose that:

H4: The indirect relationship between fear of illness and subjective psychological well-being via perceived distress is moderated by resilience, such that the relationship is weaker with increasing levels of resilience.

By integrating mediation and moderation relationships, we propose a moderated mediation model. As demonstrated in Fig.1, in our model resilience moderates the path from perceived distress to subjective psychological well-being in a mediated relationship. So, in the integrated model, we shall be evaluating the indirect effect of the interaction of perceived distress and resilience on subjective psychological well-being in the mediated relationship between fear of illness and subjective psychological well-being.

\section{Method}

\section{Sample and Data Collection}

After the continuous nation-wide lockdown in India, the cross-sectional survey was conducted online for two weeks. Data were collected through convenience sampling by sending a survey link created in 'Google forms' via social media to 450 prospective participants enrolled in various educational institutions in Jammu (India). The survey included demographic profile, details of exposure to COVID-19 related information through the media, and a battery of questionnaires. The survey was conducted in English, this language being a medium of instruction in educational institutions. Confidentiality, anonymity, and no potential threat of participation was assured at the outset. Voluntary participation was sought and informed consent was obtained electronically. 432 participants in the age range 15 to 29 years (youth) responded to the survey with an 88.89 percent response rate. 48 respondents gave unengaged responses, therefore were not retained for further analysis. Hence, the final sample size of 384 respondents. Based on inverse square root method, minimum sample size 160 is recommended for the PLS-SEM study (Kock \& Hadaya, 2018). Hence, it could be concluded that the sample of 384 was adequate.

\section{Measures}

Fear of illness. This construct was adopted from the Short Health Anxiety Scale (SHAl) (Alberts et al., 2011). The construct fear of illness comprises of five items (item 5, 8, 9, 11, 12) of the original 18-item SHAI (Salkovskis et al., 2002). The items consist of a group of four statements requiring the respondent to 
describe their feelings over the past six months in the context of COVID-19 infection/illness only. Items are scored from 0 to 3 . A sample item is "I never think I have a serious illness; I sometimes think I have a serious illness; I often think I have a serious illness; I usually think that I am seriously ill." Cronbach alpha .726 was obtained for the construct.

Perceived distress. Six negatively worded items $(1,2,3,6,9,10)$ to measure perceived distress (Hewitt et al., 1992) were borrowed from the Perceived Stress Scale (Cohen et al., 1983). The scale applies to the ongoing life conditions (Cohen \& Williamson, 1988). The responses are based on the feelings and thoughts in the last one month. Items are scored on a 5-point Likert scale, from 0 to 5 ('never' to 'very often'). For example, "In the last month, how often have you been upset because of something that happened unexpectedly?" The Cronbach's alpha obtained for this construct was .809 .

Subjective psychological well-being. The World Health Organization Well-Being Index (WHO-5 Well-being Index; Staehr, 1998) is a measure of subjective psychological well-being. The scale assesses the hedonic aspects of psychological well-being. The five items of the scale are on 6-point Likert scale ranging from 0 to 5 ('not present' to 'constantly present'). Positively worded five items in this scale cover positive mood, vitality, and general interest; such as "I have felt cheerful in good spirits." The Cronbach alpha reliability coefficient .836 was calculated for the scale in this study.

Resilience. The Brief Resilience Scale (BRS) consists of six items measuring trait resilience and assesses an ability to bounce back after exposure to stress (Smith et al., 2008). The items are scored on a 5-point Likert scale, ranging from 1 to 5 ('strongly disagree' to 'strongly agree'). A sample item is "I tend to bounce back quickly after hard times". Cronbach alpha reliability for the six items measuring resilience was .827 .

To identify the factor structure of borrowed items for the two constructs, fear of illness and psychological distress, exploratory factor analysis (EFA) was used. The detailed results are given in Table1 EFA was done on the data collected from 100 respondents separately. Kaiser-Meyer-Olkin (KMO) value was found to be greater than the threshold .50 (Hair et al., 2010). This indicated the adequacy of the sample for further analysis. As expected, the items loaded on a single factor 'fear of illness' comprising five items (Alberts et al., 2011). Further, six items of Perceived Stress Scale also converged under one factor 'perceived distress'. Therefore, these items in two constructs were used for the final data collection.

Table 1 Result of Exploratory Factor Analysis 


\begin{tabular}{|c|c|c|c|c|c|}
\hline Construct/item & $\begin{array}{l}\text { Factor } \\
\text { loading }\end{array}$ & KMO & $\begin{array}{l}\text { Eigen } \\
\text { value }\end{array}$ & $\begin{array}{l}\text { Variance } \\
\text { explained } \\
\text { (\% age) }\end{array}$ & $\begin{array}{l}\text { Cronbach } \\
\text { Alpha }\end{array}$ \\
\hline Fear of illness & & .766 & 2.519 & 50.371 & .748 \\
\hline Fear of having serious illness & .731 & & & & \\
\hline Relieved if doctor says nothing's wrong & 619 & & & & \\
\hline Hear about illness and think I have it & 648 & & & & \\
\hline Feeling at risk for developing illness & .744 & & & & \\
\hline Think I have serious illness & .792 & & & & \\
\hline Perceived distress & & .779 & 2.813 & 46.875 & .770 \\
\hline $\begin{array}{l}\text { In the last month, how often have you been upset } \\
\text { because of something that happened } \\
\text { unexpectedly? }\end{array}$ & .719 & & & & \\
\hline $\begin{array}{l}\text { In the last month, how often have you felt that you } \\
\text { were unable to control the important things in your } \\
\text { life? }\end{array}$ & .674 & & & & \\
\hline $\begin{array}{l}\text { In the last month, how often have you felt nervous } \\
\text { and "stressed"? }\end{array}$ & .762 & & & & \\
\hline $\begin{array}{l}\text { In the last month, how often have you found that } \\
\text { you could not cope with all the things that you } \\
\text { had to do? }\end{array}$ & .602 & & & & \\
\hline $\begin{array}{l}\text { In the last month, how often have you been } \\
\text { angered because of things that were outside of } \\
\text { your control? }\end{array}$ & 640 & & & & \\
\hline $\begin{array}{l}\text { In the last month, how often have you felt } \\
\text { difficulties were piling up so high that you could } \\
\text { not overcome them? }\end{array}$ & 699 & & & & \\
\hline
\end{tabular}

\section{Sample Descriptive}

The sample comprised of 270 females (70.31\%) and 114 males (29.68\%). The age ranged from 15 to 29 years $(M=24.39, S D=3.33)$. This study was carried out in the context of COVID-19. The participants provided information on media exposure. Table 2 shows a source of information related to COVID-19 on which the participants relied for information. Further, of the 384 participants, 142 (37\%), 93 (24.2\%), 149 $(38.8 \%)$ sought information once a day, twice a day, several times a day respectively.

Table 2 Source of COVID-19 Related Information 


\begin{tabular}{|lllll|}
\hline Source of Information & \multicolumn{3}{l|}{ Yes } & \\
\cline { 2 - 5 } & Frequency & Percent & Frequency & Percent \\
\hline News on Television & 286 & 74.5 & 98 & 25.5 \\
\hline Print media & 66 & 17.2 & 318 & 82.8 \\
\hline Social media & 249 & 64.8 & 135 & 35.2 \\
\hline Authentic/Government websites & 157 & 40.9 & 227 & 59.1 \\
\hline Other sources & 56 & 14.6 & 328 & 85.4 \\
\hline
\end{tabular}

This confirms that during the lockdown, participants were continually seeking COVID-19 related information from media through various sources. The reliance on the sources not considered to be authentic and the frequency of seeking information have exposed them to a lot of misinformation, and bad news related to COVID-19. This might have been overwhelming and hence the development of fear of illness.

\section{Data Analysis}

Using SPSS version 23 the exploratory factor analysis and descriptive analysis were performed. Since the current study aimed at theory building and prediction of endogenous variables, the partial least squares structural equation modeling (PLS-SEM) technique was applied (Hair et al., 2014) to test the research model. Moreover, the use of PLS-SEM is appropriate as latent variable scores were analyzed for determining predictive relevance (Hwang et al., 2020). The two-stage approach for analysis (Hair et al., 2017) was followed. Data were analyzed using the 'Smart PLS software version 3.3.2' (Ringle et al., 2015). Further, for the assessment of moderated mediation, PROCESS for SPSS was used (Hayes, 2017).

\section{Results}

\section{Common Method Bias}

Before testing the model, common method bias (CMB) for all the constructs was checked. As recommended by Kock (2015) for examining CMB in PLS-SEM, the variance inflation factor (VIF) was calculated through the full collinearity test for all latent variables in the model. Table 3 shows, full collinearity VIFs. The full collinearity VIF values for the constructs in the model in this study were below threshold 3.3 (Kock, 2015). Also, the Harman Single Factor (Podsakoff et al., 2003) largest variance was $24.063 \%$ which was lesser than $50 \%$. Hence, it confirms no CMB in this study and ascertains there is no possibility of misleading results.

\section{Measurement Model}


The constructs in our model are first-order and reflective. The convergent validity was evaluated for the reliability of items and constructs. We looked into indicator loadings, composite reliability (CR), DillionGoldstein's rho ( $\rho A)$, and average variance extracted (AVE) (see Table 3).

Hair et al. (2017) has recommended 0.70 as the threshold value for indicator loadings. However, items with outer loadings between 0.40 and 0.70 can be retained and are considered for deletion if it enhances AVE so that the minimum criterion of 0.50 is achieved (Hair et al., 2010). We retained all the indicators with loadings within a specified range as AVE was above the threshold (Hair et al., 2014), except for FOI2 (Item 8 of the original SHAl) which was deleted due to low loading. As suggested by Hair et al. (2014), Cronbach's alpha being too conservative was not considered in the evaluation of internal consistency. Raykov (1998) recommended the evaluation of composite reliability (CR). As per Hair et al. (2017), CR between 0.60 and 0.70 is acceptable in exploratory research. The CR for all the constructs of the study is above 0.80 which is satisfactory (Hair et al., 2014). However, CR is considered liberal. Dillion-Goldstein's rho ( $\rho A$ ) is the exact measure of construct reliability (Dijkstra \& Henseler, 2015). In our measurement model, $\rho A$ values are within the acceptable range. This established the internal reliability of the measurement model.

In addition, convergent validity was assessed by examining AVE which should be higher than 0.5 (Hair et al., 2014). Table 3 indicates that the convergent validity was achieved with AVE more than the threshold value 0.50 (Hair et al., 2017).

Table 3 Measurement Model Results 


\begin{tabular}{|c|c|c|c|c|c|c|}
\hline Construct & Items & Loadings & $\rho A$ & $\mathrm{CR}$ & AVE & Full collinearity VIFs \\
\hline \multirow[t]{7}{*}{ Perceived distress } & & & 0.826 & 0.862 & 0.512 & 1.438 \\
\hline & PD1 & 0.717 & & & & \\
\hline & PD2 & 0.669 & & & & \\
\hline & PD3 & 0.808 & & & & \\
\hline & PD4 & 0.577 & & & & \\
\hline & PD5 & 0.720 & & & & \\
\hline & PD6 & 0.778 & & & & \\
\hline \multirow[t]{6}{*}{ SPWB } & & & 0.840 & 0.885 & 0.606 & 1.408 \\
\hline & SPWB1 & 0.706 & & & & \\
\hline & SPWB2 & 0.811 & & & & \\
\hline & SPWB3 & 0.792 & & & & \\
\hline & SPWB4 & 0.784 & & & & \\
\hline & SPWB5 & 0.794 & & & & \\
\hline \multirow[t]{7}{*}{ Resilience } & & & 0.848 & 0.873 & 0.539 & 1.141 \\
\hline & $\mathrm{R} 1$ & 0.626 & & & & \\
\hline & R2 & 0.637 & & & & \\
\hline & R3 & 0.827 & & & & \\
\hline & $\mathrm{R} 4$ & 0.606 & & & & \\
\hline & R5 & 0.836 & & & & \\
\hline & R6 & 0.700 & & & & \\
\hline \multirow[t]{6}{*}{ Fear of illness } & & & 0.726 & 0.824 & 0.540 & 1.145 \\
\hline & FOI1 & 0.717 & & & & \\
\hline & FOI2 & Deleted & & & & \\
\hline & $\mathrm{FOI3}$ & 0.822 & & & & \\
\hline & FOI4 & 0.708 & & & & \\
\hline & FOI5 & 0.685 & & & & \\
\hline
\end{tabular}

Notes: $\rho A=$ Dillion-Goldstein's rho, $\mathrm{CR}=$ composite reliability, $\mathrm{AVE}=$ average variance explained 
Next, as suggested by Hair et al. (2019) the discriminant validity was assessed by Heterotrait-Monotrait (HTMT) ratio (Henseler et al., 2015). Table 4 clearly shows that all the values for the constructs in the model are below a conservative criterion of 0.85 (Henseler et al., 2015). This established discriminant validity among all the constructs in the model. All the constructs in the model are distinct from each other.

Table 4 Heterotrait-Monotrait (HTMT) Ratio for the Constructs

\begin{tabular}{|lllll|}
\hline & $\begin{array}{l}\text { Perceived } \\
\text { distress }\end{array}$ & Resilience & $\begin{array}{l}\text { Subjective psychological } \\
\text { well-being }\end{array}$ & $\begin{array}{l}\text { Fear of } \\
\text { illness }\end{array}$ \\
\hline Perceived distress & - & - & - & - \\
\hline Resilience & 0.383 & - & - & - \\
\hline $\begin{array}{l}\text { Subjective psychological } \\
\text { well-being }\end{array}$ & 0.596 & 0.348 & - & - \\
\hline Fear of illness & 0.408 & 0.211 & 0.368 & - \\
\hline
\end{tabular}

\section{Structural Model and Hypotheses Testing}

In the next stage of PLS-SEM, structural model results were assessed. It requires testing for the collinearity issues, structural relationships between constructs. Additionally, the model's in-sample predictive accuracy and model's out-of-sample predictive power is established (Shmueli et al., 2019).

First, the value of inner VIF was assessed. VIF should be between 0.20 and 5.00 (Hair et al., 2014). VIF values beyond 3.33 (Diamantopoulos \& Siguaw, 2006), and within 3 to 5 means collinearity issues (Mason \& Perreault Jr, 1991). Based on the inner VIF values in Table 5, all the values for the current model meets the aforementioned criteria. Hence, our model is free of collinearity issues.

Next, the significance of the proposed hypotheses was assessed. Bias accelerated bootstrap re-sampling technique with 5000 resamples was applied. The results in Table 5 show that all the hypotheses for the study were supported. Further, the results demonstrate the significant negative and direct effect of fear of illness on subjective psychological well-being $(\mathrm{H} 1)$ whereas the fear of illness has a significant positive effect on perceived distress ( $\mathrm{H} 2)$.

In addition, we validated the mediation hypothesis (H3) using the product coefficients approach (Hayes \& Scharkow, 2013). The indirect effect of fear of illness on subjective psychological well-being through perceived distress was found to be negative (Table 5). The bias-corrected bootstrap confidence interval at $95 \%$ showed mediation of perceived distress in the relationship between fear of illness and subjective psychological well-being. Furthermore, the results confirm a stronger direct effect than the indirect effect. 
Next, for the model's in-sample predictive accuracy (Dolce et al., 2017) coefficient of determination $\left(R^{2}\right)$ for endogenous constructs was examined. $R^{2}$ value of 0.100 and 0.298 was obtained for perceived distress and subjective psychological well-being, respectively. $29.8 \%$ variance of subjective psychological well-being was jointly explained by fear of illness and perceived distress. The $\mathrm{R}^{2}$ value 0.2 , as advocated by Rasoolimanesh et al. (2017), is high in behavioral sciences research. However, $\mathrm{R}^{2}$ of perceived distress also establishes substantial predictive accuracy. Next, effect size $\left(\mathrm{f}^{2}\right)$ for the significant path coefficients were considered (Table 5). $f^{2}$ value of $0.35,0.15$, and 0.02 reflects large, medium, and small effect size respectively (Cohen, 1988). In explaining perceived distress and subjective psychological well-being, fear of illness indicated a small effect size. In producing $\mathrm{R}^{2}$ of subjective psychological well-being, perceived distress showed a substantial effect. Finally, predictive relevance of the model for the endogenous construct was evaluated using Stone-Geisser's Q2 (Geisser, 1974; Stone, 1974). Blindfolding with omission distance $D=7$ obtained $Q^{2}$ value for psychological well-being (0.173) and perceived distress $(0.048)$. $Q^{2}$ value is to be higher than zero (Hair et al., 2014). This establishes predictive relevance for both endogenous constructs (Fornell \& Cha, 1994). Sufficient predictive relevance for endogenous constructs in the model was established.

Table 5 Results of Structural Model

\begin{tabular}{|llllllll|}
\hline Hypothesis & $\begin{array}{l}\text { Direct/Indirect } \\
\text { effect }\end{array}$ & $\begin{array}{l}\text { Path } \\
\text { Coefficient/Std } \\
\text { Beta }\end{array}$ & $\begin{array}{l}t- \\
\text { value }\end{array}$ & $\begin{array}{l}\text { Confidence } \\
\text { Interval }(95 \%) \\
B C a\end{array}$ & VIF & $\begin{array}{l}\text { Effect } \\
\text { size } \\
\left(f^{2}\right)\end{array}$ & Decision \\
\hline H1 & FOI->SPWB & -0.136 & 2.623 & {$[-0.220,-0.049]$} & 1.118 & 0.024 & Accepted \\
\hline H2 & FOI->PD & 0.316 & 6.173 & {$[0.221,0.392]$} & 1.000 & 0.111 & Accepted \\
\hline H3 & PD->SPWB & -0.410 & 7.750 & {$[-0.494,-0.319]$} & 1.199 & 0.200 & - \\
\hline & $\begin{array}{l}\text { FOI->PD- } \\
\text { >SPWB }\end{array}$ & -0.129 & 4.872 & {$[-0.174,-0.087]$} & & NA & Accepted \\
\hline H4a & R->SPWB & 0.147 & 3.472 & {$[0.072,0.211]$} & 1.112 & 0.028 & - \\
\hline
\end{tabular}

Notes: FOI=fear of illness, $\mathrm{PD}=$ perceived distress, $\mathrm{SPWB}=$ subjective psychological well-being, $\mathrm{R}=$ resilience.

$\mathrm{R}^{2}$ and $\mathrm{Q}^{2}$ statistic is for interpreting the model's predictive power as it indicates the model's in-sample explanatory power. We should also consider out-of-sample predictive power (Dolce et al., 2017; Nitzl \& Chin, 2017). For evaluating predictions from PLS path model estimations cross-validation was done between model training sample and a holdout sample by generating subgroups based on criteria of $k=10$ (Shmueli et al., 2019). The mean absolute error (MAE) and root mean squared error (RMSE) came out to be 0.741 and 0.939 respectively. The positive $Q^{2}{ }_{\text {predict }}$ value of 0.128 and ). 090 for the construct perceived distress and subjective psychological well-being respectively reflects the desirable predictive relevance of the PLS-SEM model. Further, RMSE and MAE at the item level for the PLS model and regression model were compared. 
RMSE and MAE of most of the indicators of subjective psychological well-being for the PLS model are smaller than LM and $Q^{2}{ }_{\text {predict }}$ values for the PLS model are larger than for LM (Table 6). Therefore, the model has a medium out of sample predictive power.

Table 6 PLS Indicator Prediction Summary

\begin{tabular}{|llllllllll|}
\hline & PLS & & \multicolumn{3}{c|}{ LM } & \multicolumn{5}{c|}{ PLS-LM } \\
Item & $R M S E$ & $M A E$ & $Q_{\text {predict }}^{2}$ & $R M S E$ & $M A E$ & $Q^{2}$ predict & $R M S E$ & $M A E$ & $Q_{\text {predict }}^{2}$ \\
PD1 & 0.967 & 0.688 & 0.041 & 0.958 & 0.718 & 0.059 & 0.009 & -0.03 & -0.018 \\
\hline PD2 & 1.081 & 0.834 & 0.014 & 1.078 & 0.855 & 0.018 & 1.003 & -0.021 & -0.004 \\
PD3 & 1.074 & 0.825 & 0.051 & 1.081 & 0.834 & 0.039 & -0.007 & -0.009 & 0.016 \\
\hline PD4 & 0.948 & 0.749 & 0.038 & 0.948 & 0.745 & 0.036 & 0.000 & 0.004 & 0.004 \\
PD5 & 1.068 & 0.839 & 0.073 & 1.073 & 0.847 & 0.066 & -0.005 & -0.008 & 0.013 \\
\hline PD6 & 1.035 & 0.839 & 0.058 & 1.046 & 0.835 & 0.036 & -0.011 & 0.004 & -0.015 \\
\hline SPWB1 & 1.148 & 0.879 & 0.032 & 1.152 & 0.882 & 0.025 & -0.004 & -0.003 & 0.007 \\
\hline SPWB2 & 1.126 & 0.906 & 0.110 & 1.122 & 0.895 & 0.116 & 0.004 & 0.011 & -0.006 \\
\hline SPWB3 & 1.165 & 0.934 & 0.067 & 1.181 & 0.948 & 0.041 & -0.016 & -0.014 & 0.030 \\
\hline SPWB4 & 1.306 & 1.079 & 0.090 & 1.338 & 1.092 & 0.045 & -0.032 & -0.013 & 0.045 \\
\hline SPWB5 & 1.282 & 1.039 & 0.088 & 1.309 & 1.055 & 0.049 & -0.027 & -0.016 & 0.043 \\
\hline
\end{tabular}

Note: RMSE= root mean squared error, $\mathrm{MAE}=$ mean absolute error, PLS-partial least squares, $\mathrm{LM}=$ linear regression model.

The results reflect the indirect effect of fear of illness on the subjective psychological well-being through perceived distress. Next, the conditional process model was applied in which the mediation model was extended with the moderation of resilience on the relationship between perceived distress and subjective psychological well-being (Andrew Hayes Process Model No. 14). The interaction of perceived distress and resilience is significantly predicting subjective psychological well-being (Table 5). Therefore, we can conclude that resilience moderates between perceived distress and subjective psychological well-being relationship. Hence, the proposed moderating hypothesis 4 a stands accepted. Subsequently, the index of moderated mediation was calculated to evaluate the conditional process (Hayes, 2015). The calculated index came out to be 0.027 , Boot SE $=0.014$ with $(95 \% \mathrm{BCa} \mathrm{Cl}: 0.001$ to 0.056$)$. As the null of zero does not fall between confidence interval, we infer that the indirect effect is conditional on the level of resilience. The result supports the moderated mediation hypothesis $(\mathrm{H} 4)$. Hence, resilience significantly moderated the indirect effect of fear of illness on subjective psychological well-being. Having established the existence of 
moderated mediation, the spotlight analysis was conducted next (Spiller et al., 2008). Table 7 shows all three indirect effects for subjective psychological well-being with low, medium and high resilience groups were negative and significant as the confidence interval does not include zero. Further, pairwise contrasts were also significant indicating that the indirect effects were conditional on the level of resilience. This leads to the conclusion that the fear of illness lowers subjective psychological well-being via perceived distress and the influence of the mediator is reversed with an increase in subjective psychological well-being due to the increment of resilience. In addition, Fig. 2 shows that the slopes become less negative as we move from low to high resilience. Overall, these results support the conditional effect of the indirect effect of fear of illness on subjective psychological well-being.

Table 7 Conditional Indirect Effects at Values of the Resilience

\begin{tabular}{|llllll|}
\hline Outcome variable & Moderator & Effect & BootSE & Boot LLCl & Boot ULCl \\
\hline SPWB & -1.0013 (low) & -0.156 & 0.033 & -0.224 & -0.093 \\
SPWB & .0000 (moderate) & -0.129 & 0.027 & -.0184 & -0.078 \\
SPWB & 1.0013 (high) & -0.102 & 0.027 & -0.159 & -0.052 \\
\hline
\end{tabular}

\section{Discussions}

The COVID-19 pandemic has affected the mental health of people across the world. With the outbreak of COVID-19, many studies have been carried out to assess the negative and positive mental health outcomes. This study highlights the process that weakens the negative relationship between fear of illness and subjective psychological well-being through resilience (moderator) and perceived distress (mediator) thus enhancing subjective psychological well-being. To our knowledge, this is the first integrated moderated mediation model which has explained the process through which subjective psychological well-being is promoted.

Results from the current study show the direct effect of fear of illness on subjective psychological well-being. The results of this study are consistent with previous evidence indicating the association between fear of illness and subjective psychological well-being (Amin, 2020; Ahuja et al., 2020; Blasco-Belled et al., 2020; Paredes et al., 2020; Satici et al., 2020; Serafini et al., 2020). Hereby, these results suggest that due to fear of illness during current pandemic, perceived subjective psychological well-being decreases. We found that perceived distress was predicted positively by fear of illness, which is in line with previous studies showing that symptoms of psychological distress are experienced during an outbreak of diseases (Hsing et al., 2020; Newby et al., 2020; Parlapani et al., 2020; Satici et al., 2020). This could act as a challenge in coping up with the adversity and pose a threat to positive mental health. Prior research demonstrates the negative effect of perceived distress on subjective psychological well-being (Jiang, 2020; Meng \& D'Arcy, 2016; Tecson et al., 2019).

Fear is the prominent reaction to the pandemic (Ahorsu et al., 2020). With the lockdown, people spent time in the home but got exposure to pandemic through media. Thus, information on COVID-19 might have acted as 
a stressor resulting in fear of contracting COVID-19 (Lin, 2020). Fear underlies all mental health problems (Polizzi et al., 2020). Notably, it is well established that the inaccurate information flowing from social media (Cinelli et al., 2020), blizzard of bad and fake news make people conscious of the looming appalling dangers (Torales et al., 2020; Kumar \& Nayar, 2020). Hence, due to apocalyptic views and irrational fear of illness people during pandemics are more prone to perceive distress. In the current pandemic, the risk of spread of infection, lethality, coupled with sudden lockdown has predisposed people to develop psychiatric disorders (Kumar \& Nayar, 2020; Satici et al., 2020). Albeit the passive stance with the feeling of helplessness has developed in the crevices of mind, making the people accept that they cannot control the virus and save themselves from any harm. For such people, if timely preventive steps are not taken, symptoms of psychological distress might develop signifying the possible development of psychiatric conditions.

The study findings revealed that the effect of fear of illness on subjective psychological well-being is mediated by perceived distress. Perceived distress predicts subjective psychological well-being (Meng \& D'Arcy, 2016). The study findings confirm the negative indirect effect of fear of illness on subjective psychological well-being. It implies subjective psychological well-being further deteriorates when fear of illness results in psychological distress. Recent studies have indeed reported psychological distress within the context of the COVID-19 pandemic (Boyraz \& Legros, 2020; Wang et al., 2020). During challenging times, these symptoms might be exacerbated. It is a matter of high concern and it cannot be left ignored. Furthermore, failure to implement timely measures and handle perceived distress might give rise to numerous other negative mental health outcomes even in post COVID-19 period.

Finally, this study revealed that resilience moderates the mediated relationship between fear of illness and subjective psychological well-being. These results corroborate previous empirical data on the role of resilience as a moderator of negative outcomes after exposure to stressful events. The interaction of perceived distress with resilience enhances subjective psychological well-being. This study has garnered more evidence in support of the protective function of resilience. Resilience has an inverse relationship with psychological distress and a positive relationship with various measures of subjective well-being such as happiness, quality of life, and life satisfaction (Tecson et al., 2019). With the introduction of resilience, the effect of perceived distress relinquishes. It could be said that resilience enables individuals to regulate the perceived distress in adversities. Hence, it helps in coping and diminishes perceived distress and enhances subjective psychological well-being especially during adverse life situations which act as a major threat to mental health.

Our study demonstrates that both indirect and direct relationship is significant and also it is conditional on resilience level. It could be said that resilience buffered the negative effect of fear of illness through perceived distress on subjective psychological well-being. Hence, in the presence of resilience, the perceived distress resulting from the fear of COVID-19 fails to further lower the positive mental health. The psychological distress fails to have any deleterious effect as resilience fosters psychological well-being. Furthermore, positive mental health is attained as people might end up exhibiting better condition than the one experienced prior to exposure to trauma (Southwick et al., 2014). This outcome corresponds well with the Strength Model of positive psychology. Resilience is a strength (Färber \& Rosendahl, 2018) which contributes to enhancing well-being and mitigating the negative mental health outcomes (Tecson et al.,

Page 16/28 
2019; Rashid \& Seligman, 2018; Yildirim \& Arslan, 2020). In adverse life circumstances, resilience acts as a protective agent hence the positive outcomes (Bonanno, 2004; Nishikawa, 2006). Resilient people can cope with the stressors during adversity (Connor \& Davidson, 2003). Therefore, in the face of adversity, it is possible to have positive outcomes.

The findings of our study contribute to the understanding of the factors responsible for subjective psychological well-being during traumatic and adverse conditions. It has become evident that the level of subjective psychological well-being during pandemics accrues from fear of illness which increases perceived distress but is buffered by the presence of resilience. Interestingly, Charney (2004) emphasized that the fear experienced due to traumatic stress could be dealt with resilience. Our results confirmed that resilience is an important resource that acts in adverse life situations. Further, resilient people do not succumb to adversity and are able to evolve out of it. Bolier et al. (2013) suggested that positive psychology interventions could be effective in reducing psychological distress and enhancing subjective well-being among the general population. These results reiterate the importance of building resilience to promote and maintain positive mental health and mitigate the effects of negative mental health.

Therefore, it could be said that adverse life situations such as a sudden outbreak of diseases affect the mental health of the people even when they are not exposed to it directly. The fear of illness or contracting infection might arise through constant exposure to the information related to the disease. The fear of illness has a propensity to affect both positive and negative mental health. If timely measures are not taken to prevent the negative mental outcomes and mitigate its occurrence then it might further affect the subjective psychological well-being. The level of resilience is important for how well an individual copes with stress exposure. In terms of COVID-19 as a stressor, persons high on resilience are less likely to have poor mental health compared to those with low resilience factors.

\section{Theoretical Contributions}

The findings of our study are in alignment with the Competence-based Model of mental health proposed by positive psychology. Positive psychology demands a shift from a deficit-based model to a health-promoting model that relies on protective functions for the promotion of positive mental health. Hence, the moderating role of resilience is in confirmation with the Strength Model which focuses mainly on the building of strengths and promotion of positive mental health. Resilience acts as a salutogen that mitigates the effect of perceived distress and increases subjective psychological well-being.

\section{Practical Implications}

The specific findings have implications for counseling. First, our findings suggest that resilience could serve as a buffer for people experiencing the signs of psychological distress due to the fear of illness during COVID-19 pandemic. In other words, resilience can prevent the development of psychiatric conditions during adverse life circumstances and can improve well-being. Second, the role played by resilience is of vital importance. Therefore, efforts aimed at enhancing resilience could accentuate levels of subjective 
psychological well-being. Thirdly, the findings of the present study may be of relevance when studying the importance of resilience during a national and global crisis for developing preventive actions. In the context of pandemics characterized by sudden changes, abound by stressors, building resilience is important to attain positive mental health. Fourthly, prophylactic measures are desirable during prolonged adversity to combat the mental health problems arising due to exposure to media.

\section{Limitations and Future Studies}

There are some limitations in this study which future research could address.

Firstly, the study is cross-sectional in nature. A longitudinal study should be conducted in the future to bring out the long-term effects of resilience as a protective factor in the maintenance of mental health. We need to follow people over time to ascertain the relevance of resilience in post COVID-19 period as well as during the prolonged period of the ongoing pandemic.

Secondly, The current study is limited to a convenience sample of youth from the general population. Due to the online mode of administering questionnaires via social media children and the elderly were not contacted. The representation of a specific age group may have affected the results. For generalizing the current findings, studies are to be conducted on the representative samples of diverse age groups in the general population.

Thirdly, the results of this research, indicated $R^{2}$ of 0.200 for subjective psychological well-being, suggesting fear of illness, perceived distress and resilience explained $20 \%$ variance in subjective psychological wellbeing. This means, $80 \%$ variance in subjective psychological well-being is explained by factors that are not in the model. Future studies may explore the role of other variables that would act as protective factors and facilitate coping during adversities.

Fourthly, although fear of illness was assessed, our findings bolster the suggestion that exposure to information about the pandemic through media is an important purveyor of mental health. Future research may wish to explore the extent of the impact of exposure to information from media on fear of illness and mental health.

Lastly, the current study underscored the augmentation of resilience in the promotion of positive mental health and prevention of negative mental health. Thus, well-designed intervention studies are needed to determine the efficacy of resilience in bringing about desirable outcomes in adverse life situations.

\section{Conclusions}

The study of the moderated-mediation resulting in enhanced psychological well-being seems timely and necessary within the context of the COVID-19 pandemic. Our findings add to the existing literature by explaining the mechanism which makes it possible for an individual to remain unscathed even when distress is perceived especially during pandemics. In the current study, we have given due importance to both positive and negative mental health. The results indicate that it will be beneficial to apply interventions to build 
resilience within the context of pandemics and similar adverse life situations. However, the interventions to build resilience for the promotion of positive mental health that might be given in the ongoing traumatic phase of COVID-19 or similar type of pandemics are yet to be tested and tried.

\section{Declarations}

Conflict of Interests: The authors declare that they have no conflict of interest.

Availability of data and material: Not applicable.

Code availability: Not applicable.

Ethics Approval: We are ensuring quality and integrity of our research.

Informed Consent: Informed consent was obtained from all individual participants included in this study.

\section{References}

Abramson, A. (2020, April 8). How COVID-19 may increase domestic violence and child abuse. American Psychological Association. https://www.apa.org/topics/covid-19/domestic-violence-child-abuse. Accessed 18 September 2020.

Ahorsu, D. K., Lin, C. Y., Imani, V., Saffari, M., Griffiths, M. D., \& Pakpour, A. H. (2020). The Fear of COVID-19 Scale: Development and initial validation. International Journal of Mental Health and Addiction, https://doi.org/10.1007/s11469-020-00270-8

Ahuja, K. K., Banerjee, D., Chaudhary, K., \& Gidwani, C. (2020). Fear, xenophobia and collectivism as predictors of well-being during coronavirus disease 2019: An empirical study from India. International Journal of Social Psychiatry, https://doi.org/10.1177\%2F0020764020936323

Alberts, N. M., Sharpe, D., Kehler, M. D., \& Hadjistavropoulos, H. D. (2011). Health anxiety: Comparison of the latent structure in medical and non-medical samples. Journal of Anxiety Disorders, 25(4), 612-614. https://doi.org/10.1016/j.janxdis.2011.01.011

Amin, S. (2020). The psychology of coronavirus fear: Are healthcare professionals suffering from coronaphobia? International Journal of Healthcare Management, 13(3), 249-256.

https://doi.org/10.1080/20479700.2020.1765119

Bakioğlu, F., Korkmaz, O., \& Ercan, H. (2020). Fear of COVID-19 and positivity: Mediating role of intolerance of uncertainty, depression, anxiety, and stress. International Journal of Mental Health and Addiction, 1. https://doi.org/10.1007/s11469-020-00331-y

Blasco-Belled, A., Tejada-Gallardo, C., Torrelles-Nadal, C., \& Alsinet, C. (2020). The costs of the COVID-19 on subjective well-being: An analysis of the outbreak in Spain. Sustainability, 12(15), 6243.

https://doi.org/10.3390/su12156243

Page 19/28 
Bolier, L., Haverman, M., Westerhof, G. J., Riper, H., Smit, F., \& Bohlmeijer, E. (2013). Positive psychology interventions: A meta-analysis of randomized controlled studies. BMC Public Health, 13(1), 119.

https://doi.org/10.1186/1471-2458-13-119

Bonanno, G. A. (2004). Loss, trauma, and human resilience: Have we underestimated the human capacity to thrive after extremely aversive events? American Psychologist, 59, 20-28. https://doi.org/10.1037/0003066X.59.1.20

Bonanno, G. A., Ho, S. M., Chan, J. C., Kwong, R. S., Cheung, C. K., Wong, C. P., \& Wong, V. C. (2008). Psychological resilience and dysfunction among hospitalized survivors of the SARS epidemic in Hong Kong: A latent class approach. Health Psychology, 27(5), 659-667. https://doi.org/10.1037/0278-6133.27.5.659

Boyraz, G., \& Legros, D. N. (2020). Coronavirus Disease (COVID-19) and Traumatic Stress: Probable risk factors and correlates of posttraumatic stress disorder. Journal of Loss and Trauma, 1-20.

https://doi.org/10.1080/15325024.2020.1763556

Charney, D. S. (2004). Psychobiological mechanisms of resilience and vulnerability: Implications for successful adaptation to extreme stress. American Journal of Psychiatry, 161(2), 195-216. https://doi.org/10.1176/appi.ajp.161.2.195

Chen, B., Li, Q. X., Zhang, H., Zhu, J. Y., Yang, X., Wu, Y. H., ... \& Chen, Z. T. (2020). The psychological impact of COVID-19 outbreak on medical staff and the general public. Current Psychology, 1-9.

https://doi.org/10.1007/s12144-020-01109-0

Cinelli, M., Quattrociocchi, W., Galeazzi, A., Valensise, C. M., Brugnoli, E., Schmidt, A. L., ... \& Scala, A. (2020). The covid-19 social media infodemic. arXiv:2003.05004. https://doi.org/10.1038/s41598-020-73510-5

Cohen, J. (1988). Statistical power analysis for the behavioral sciences, Second Ed., New Jersey: Hillsdale, Lawrence Earlbaum Associates.

Cohen, S., Kamarck, T., \& Mermelstein, R. (1983). A global measure of perceived stress. Journal of Health and Social Behavior, 385-396. https://doi.org/10.2307/2136404

Cohen, S., \& Williamson, G. (1988). Perceived stress in a probability sample in the United States. In S. Spacapan and S.Oskamp (Eds.), The social psychology of health (pp. 31-67). Newbury Park: Sage.

Connor, K. M., \& Davidson, J. R. T. (2003). Development of a new resilience scale: The Connor-Davidson resilience scale (CD-RISC). Depression and Anxiety, 18, 76-82.

Cuhadar, D., Tanriverdi, D., Pehlivan, M., Kurnaz, G., \& Alkan, S. (2016). Determination of the psychiatric symptoms and psychological resilience levels of hematopoietic stem cell transplant patients and their relatives. European Journal of Cancer Care, 25(1), 112-121. https://doi.org/10.1111/ecc.12219

Diamantopoulos, A., \& Siguaw, J. A. (2006). Formative versus reflective indicators in organizational measure development: A comparison and empirical illustration. British Journal of Management, 17(4), $263-282$. 
Diener, E., \& Lucas, R. E. (2000). Subjective emotional well-being. In M. Lewis, \& J.M. Haviland (Eds.), Handbook of emotions (2nd ed.) (pp. 325-337). New York: Guilford.

Dijkstra, T. K., \& Henseler, J. (2015). Consistent and asymptotically normal PLS estimators for linear structural equations. Computational Statistics \& Data Analysis, 81, 10-23.

https://doi.org/10.1016/j.csda.2014.07.008

Dolce, P., Esposito Vinzi, V., \& Lauro, C. (2017). Predictive path modeling through PLS and other componentbased approaches: Methodological issues and performance evaluation. In H. Latan and R. Noonan (Eds.) Partial least squares path modeling: Basicconcepts, methodological issues and applications (pp. 153-172). Cham: Springer International Publishing.

Färber, F., \& Rosendahl, J. (2018). The association between resilience and mental health in the somatically ill: A systematic review and meta-analysis. Deutsches Ärzteblatt International, 115(38), 621. https://doi.org/10.3238/arztebl.2018.0621

Fornell, C., \& Cha, J. (1994) Partial least squares. In R. P. Bagozzi (Ed.), Advanced methods in marketing research (pp. 52-78). Cambridge: Blackwell.

Geisser, S. (1974). A predictive approach to the random effect model. Biometrika, 61(1), 101-107. https://doi.org/10.1093/biomet/61.1.101

Hair, J. F., Black, W. C., Babin, B. J., Anderson, R. E., \& Tatham, R. L. (2010). Multivariate data analysis (7 $7^{\text {th }}$ Ed). Upper Saddle River, NJ: Pearson/Prentice Hall.

Hair, J. F., Hult, G. T., Ringle, C. M., \& Sarstedt, M. (2014). A primer on partial least squares structural equation modeling(PLS-SEM). Thousand Oaks, Sage Publications.

Hair, J. F., Sarstedt, M., \& Ringle, C. M. (2019). Rethinking some of the rethinking of partial least squares. European Journal of Marketing, 53, 566-584. https://doi.org/10.1108/EJM-10-2018-0665

Hair, J. F., Sarstedt, M., Ringle, C. M., \& Gudergan, S. P. (2017). Advanced issues in partial least squares structural equations modeling (PLS-SEM). Thousand Oaks, Sage Publications.

Harper, C. A., Satchell, L. P., Fido, D., \& Latzman, R. D. (2020). Functional fear predicts public health compliance in the COVID-19 pandemic. International Journal of Mental Health and Addiction. https://doi.org/10.1007/s11469-020-00281-5

Hayes, A. F. (2015). An index and test of linear moderated mediation. Multivariate Behavioral Research, 50(1), 1-22. https://doi.org/10.1080/00273171.2014.962683

Hayes, A. F., \& Scharkow, M. (2013). The relative trustworthiness of inferential tests of the indirect effect in statistical mediation analysis: Does method really matter?. Psychological science, 24(10), 1918-1927. 
Hayes, A. F. (2017). Introduction to mediation, moderation, and conditional process analysis: A regressionbased approach. New York: Guilford Publications.

Henseler, J., Ringle, C. M., \& Sarstedt, M. (2015). A new criterion for assessing discriminant validity in variance-based structural equation modeling. Journal of the Academy of Marketing Science, 43(1), 115-135. https://doi.org/10.1007/s11747-014-0403-8

Hewitt, P. L., Flett, G. L., \& Mosher, S. W. (1992). The Perceived Stress Scale: Factor structure and relation to depression symptoms in a psychiatric sample. Journal of Psychopathology and Behavioral Assessment, 14, 247-257. https://doi.org/10.1007/BF00962631

Hsing, A., Zhang, J. S., Peng, K., Lin, W. K., Wu, Y. H., Hsing, J. C., ... \& Lounsbury, D. W. (2020). A rapid assessment of psychological distress and well-being: Impact of the COVID-19 pandemic and shelter-inplace. Available at SSRN 3578809. http://dx.doi.org/10.2139/ssrn.3578809

Huppert, F. A. (2009). Psychological well-being: Evidence regarding its causes and consequences. Applied Psychology: Health and Well-Being, 1, 137-164. doi:10.1111/j.1758-0854.2009.01008.x

Hwang, H., Sarstedt, M., Cheah, J. H., \&Ringle, C. M. (2020). A concept analysis of methodological research on composite-based structural equation modeling: Bridging PLSPM and GSCA. Behaviormetrika, 47(1), 219241. https://doi.org/10.1007/s41237-019-00085-5

Jiang, S. (2020). Psychological well-being and distress in adolescents: An investigation into associations with poverty, peer victimization, and self-esteem. Children and Youth Services Review, 111. https://doi.org/10.1016/j.childyouth.2020.104824

Kane, S. (2019, March 5). Factors linked to psychological distress. Psych Central. Retrieved on August 14, 2020, from https://psychcentral.com/lib/factors-linked-to-psychological-distress/

Kock, N. (2015). Common method bias in PLS-SEM: A full collinearity assessment approach. International Journal of e-Collaboration 11(4), 1-10. https://doi.org/10.4018/ijec.2015100101

Kock, N., \& Hadaya, P. (2018).Minimum sample size estimation in PLS SEM: The inverse square root and gamma-exponential methods. Information Systems Journal, 28(1), 227-261.

https://doi.org/10.1111/isj.12131

Kumar, A., \& Nayar, K. R. (2020). COVID 19 and its mental health consequences. Journal of Mental Health, 12. https://doi.org/10.1080/09638237.2020.1757052

Lin, C.-Y. (2020). Social reaction toward the 2019 novel coronavirus (COVID-19). Social Health and Behavior, 3(1), 1-2. https://doi.org/10.4103/SHB.SHB_11_20 
Luthans, F. \& Church, A. H. (2002). Positive organizational behavior: Developing and managing psychological strengths. Academy of Management Perspectives, 16(1), 57-72.

https://doi.org/10.5465/ame.2002.6640181

Mamun, M. A., \& Griffiths, M. D. (2020). First COVID-19 suicide case in Bangladesh due to fear of COVID-19 and xenophobia: Possible suicide prevention strategies. Asian Journal of Psychiatry, 51. https://doi.org/10.1016/j.ajp.2020.102073

Mankiewicz, P. D., Gresswell, D. M., \& Turner, C. (2013).Subjective wellbeing in phychosis: Mediating effects of psychological distress on happiness levels amongst individuals diagnosed with paranoid schizophrenia. International Journal of Wellbeing, 3(1), 35-59. doi:10.5502/ijw.v3i1.3

Masten, A. S. (2001). Ordinary magic: Resilience processes in development. American Psychologist, 56(3), 227-238. https://doi.org/10.1037/0003-066X.56.3.227

Mason, C. H., \& Perreault Jr, W. D. (1991). Collinearity, power, and interpretation of multiple regression analysis. Journal of Marketing Research, 28(3), 268-280. https://doi.org/10.1177\%2F002224379102800302

Meng, X., \& D'Arcy, C. (2016). Coping strategies and distress reduction in psychological well-being? A structural equation modelling analysis using a national population sample. Epidemiology and Psychiatric Sciences, 25(4), 370-383. https://doi.org/10.1017/S2045796015000505

Min, H., Kim, H. J., \& Lee, S. B. (2015). Extending the challenge-hindrance stressor framework: The role of psychological capital. International Journal of Hospitality Management, 50, 105-114.

https://doi.org/10.1016/j.jhm.2015.07.006

Newby, J., O'Moore, K., Tang, S., Christensen, H., \& Faasse, K. (2020). Acute mental health responses during the COVID-19 pandemic in Australia. medRxiv. https://doi.org/10.1371/journal.pone.0236562

Nishikawa, Y. (2006). Thriving in the face of adversity: Perceptions of elementary-school principals. La Verne, CA: University of La Verne.

Nitzl, C., \& Chin, W. W. (2017). The case of partial least squares (PLS) path modeling in managerial accounting research. Journal of Management Control, 28(2), 137-156. https://doi.org/10.1007/s00187-0170249-6

Otu, A., Charles, C. H., \& Yaya, S. (2020). Mental health and psychosocial well-being during the COVID-19 pandemic: The invisible elephant in the room. International Journal of Mental Health Systems, 14(1), 1-5. https://doi.org/10.1186/s13033-020-00371-w

Pappas, G., Kiriaze, I. J., Giannakis, P., \& Falagas, M. E. (2009). Psychosocial consequences of infectious diseases. Clinical Microbiology and Infection, 15(8), 743-747. https://doi.org/10.1111/j.1469-

0691.2009.02947.x 
Paredes, M. R., Apaolaza, V., Fernandez-Robin, C., Hartmann, P., \& Yañez-Martinez, D. (2020). The impact of the COVID-19 pandemic on subjective mental well-being: The interplay of perceived threat, future anxiety and resilience. Personality and Individual Differences, 170. https://doi.org/10.1016/j.paid.2020.110455

Parlapani, E., Holeva, V., Voitsidis, P., Blekas, A., Gliatas, I., Porfyri, G. N., ... \& Bairachtari, V. (2020). Psychological and behavioral responses to the COVID-19 pandemic in Greece. Frontiers in Psychiatry, 11, 821. https://doi.org/10.3389/fpsyt.2020.00821

Pine, D. S., Costello, J., \& Masten, A. (2005). Trauma, proximity, and developmental psychopathology:The effects of war and terrorism on children. Neuropsychopharmacology, 30(10), 1781-1792. https://doi.org/10.1038/sj.npp.1300814

Podsakoff, P. M., MacKenzie, S. B., Lee, J. Y., \& Podsakoff, N. P. (2003). Common method biases in behavioral research: a critical review of the literature and recommended remedies. Journal of Applied Psychology, 88(5), 879-903.

Polizzi, C., Lynn, S. J., \& Perry, A. (2020). Stress and coping in the time of COVID-19: Pathways to resilience and recovery. Clinical Neuropsychiatry, 17(2), 59-62. https://doi.org/10.36131/CN20200204

Rashid, T., \& McGrath, R. E. (2020). Strengths based actions to enhance wellbeing in the time of COVID-19. International Journal of Wellbeing, 10(4), 113-132. Available at: https://www.internationaljournalofwellbeing.org/index.php/ijow

Rashid, T., \& Seligman, M. E. P. (2018). Positive psychotherapy: Clinical manual. Oxford University Press. Rasoolimanesh, S. M., Jaafar, M., Kock, N., \& Ahmad, A. G. (2017). The effects of community factors on residents' perceptions toward World Heritage Site inscription and sustainable tourism development. Journal of Sustainable Tourism, 25(2), 198-216. https://doi.org/10.1080/09669582.2016.1195836

Raykov, T. (1998). Coefficient alpha and composite reliability with interrelated non homogeneous items. Applied Psychological Measurement, 22(4), 375-385.

https://doi.org/10.1177\%2F014662169802200407

Ringle, C. M., Wende, S., \& Becker, J.M. (2015). "SmartPLS 3." Boenningstedt: SmartPLS GmbH. http://www.smartpls.com

Salkovskis, P. M., Rimes, K. A., Warwick, H. M. C., \& Clark, D. M. (2002). The Health Anxiety Inventory: Development and validation of scales for the measurement of health anxiety and hypochondriasis. Psychological Medicine, 32, 843-853. https://doi.org/10.1017/s0033291702005822

Satici, S. A. (2016). Psychological vulnerability, resilience, and subjective well-being: The mediating role of hope. Personality and Individual Differences, 102, 68-73. https://doi.org/10.1016/j.paid.2016.06.057

Satici, B., Gocet-Tekin, E., Deniz, M. E., \& Satici, S. A. (2020). Adaptation of the Fear of COVID-19 Scale: Its association with psychological distress and life satisfaction in Turkey. International Journal of Mental 
Serafini, G., Parmigiani, B., Amerio, A., Aguglia, A., Sher, L., \& Amore, M. (2020). The psychological impact of COVID-19 on the mental health in the general population. QJM: An International Journal of Medicine, 113(8), 531-537. https://doi.org/10.1093/qjmed/hcaa201

Shapero, B. G., Farabaugh, A., Terechina, O., DeCross, S., Cheung, J. C., Fava, M., \& Holt, D. J. (2019). Understanding the effects of emotional reactivity on depression and suicidal thoughts and behaviors: Moderating effects of childhood adversity and resilience. Journal of Affective Disorders, 245, 419-427. https://doi.org/10.1016/j.jad.2018.11.033

Shigemura, J., Ursano, R. J., Morganstein, J. C., Kurosawa, M., \& Benedek, D. M. (2020). Public responses to the novel 2019 coronavirus (2019-nCoV) in Japan: Mental health consequences and target populations. Psychiatry and Clinical Neurosciences, 74(4), 281-282. https://doi.org/10.1111/pcn.12988

Shmueli, G., Sarstedt, M., Hair, J. F., Cheah, J. H., Ting, H., Vaithilingam, S., \& Ringle, C. M. (2019). Predictive model assessment in PLS-SEM: Guidelines for using PLSpredict. European Journal of Marketing, 53(11), 2322-2347. https://doi.org/10.1108/EJM-02-2019-0189

Smith, B. W., Dalen, J., Wiggins, K., Tooley, E., Christopher, P., \& Bernard, J. (2008). The Brief Resilience Scale: Assessing the ability to bounce back. International Journal of Behavioral Medicine, 15(3), 194-200. https://doi.org/10.1080/10705500802222972

Southwick, S. M., Bonanno, G. A., Masten, A. S., Panter-Brick, C., \& Yehuda, R. (2014). Resilience definitions, theory, and challenges: Interdisciplinary perspectives. European Journal of Psychotraumatology, 5(1), 25338. https://doi.org/10.3402/ejpt.v5.25338

Spiller, S. A., Fitzsimons, G. J., Lynch, J. G., \& Mccleland, G. H. (2008). Spotlights, floodlights, and the magic number zero: Simple effects tests in moderated regression. Journal of Marketing Research, 50(2), 277-288. https://doi.org/10.1509\%2Fjmr.12.0420

Srivastava, K. (2011). Positive mental health and its relationship with resilience. Industrial Psychiatry Journal, 20(2), 75-76. https://doi.org/10.4103/0972-6748.102469

Staehr, J. K., (1998). The use of well-being measures in primary health care - the DepCare project. World Health Organization Regional Office for Europe: Well-Being Measures in Primary Health Care-the DepCare Project. Geneva: World Health Organization.

Stone, M. (1974). Cross-validatory choice and assessment of statistical predictions. Journal of the Royal Statistical Society. Series B (Methodological), 36(2), 111-147. https://doi.org/10.1111/j.25176161.1974.tb00994.x

Su, Y., \& Chen, S. (2015). Emerging posttraumatic growth: A prospective study with pre- and posttrauma psychological predictors. Psychological Trauma: Theory, Research, Practice, and Policy, 7(2), 103-111. http://dx.doi.org/10.1037/tra0000008 
Suldo, S. M., \& Shaffer, E. J. (2008). Looking beyond psychopathology: The dual-factor model of mental health in youth. School Psychology Review, 37(1), 52. https://doi.org/10.1080/02796015.2008.12087908

Tecson, K. M., Wilkinson, L. R., Smith, B., \& Ko, J. M. (2019, October). Association between psychological resilience and subjective well-being in older adults living with chronic illness. In Baylor University Medical Center Proceedings (Vol. 32, No. 4, pp. 520-524). Taylor \& Francis.

https://doi.org/10.1080/08998280.2019.1625660

Torales, J., O'Higgins, M., Castaldelli-Maia, J. M., \& Ventriglio, A. (2020). The outbreak of COVID-19 coronavirus and its impact on global mental health. International Journal of Social Psychiatry, 66(4), 317320. https://doi.org/10.1177\%2F0020764020915212

Vahedian-Azimi, A., Moayed, M. S., Rahimibashar, F., Shojaei, S., Ashtari, S., \& Pourhoseingholi, M. A. (2020). Comparison of the severity of psychological distress among four groups of an Iranian population regarding COVID-19 pandemic. BMC Psychiatry, 20(1), 1-7. https://doi.org/10.1186/s12888-020-02804-9

Vieselmeyer, J., Holguin, J., \& Mezulis, A. (2017). The role of resilience and gratitude in posttraumatic stress and growth following a campus shooting. Psychological Trauma: Theory, Research, Practice, and Policy, 9(1), 62-69. https://doi.org/10.1037/tra0000149

Wang, C., Pan, R., Wan, X., Tan, Y., Xu, L., Ho, C. S., \& Ho, R. C. (2020). Immediate psychological responses and associated factors during the initial stage of the 2019 coronavirus disease (COVID-19) epidemic among the general population in China. International Journal of Environmental Research and Public Health, 17(5), 1729. https://doi.org/10.3390/ijerph17051729

Winefield, H. R., Gill, T. K., Taylor, A. W., \& Pilkington, R. M. (2012). Psychological well-being and psychological distress: Is it necessary to measure both?. Psychology of Well-Being, 2(1), 3. https://doi.org/10.1186/22111522-2-3

Yildirim, M., \& Arslan, G. (2020). Exploring the associations between resilience, dispositional hope, subjective well-being, and psychological health among adults during early stage of COVID-19. Current Psychology. Advance online publication. https://doi.org/10.1007/s12144-020-01177-2

Zacher, H., \& Rudolph, C. W. (2020). Individual differences and changes in subjective wellbeing during the early stages of the COVID-19 pandemic. American Psychologist. Advance online publication. https://doi.org/10.1037/amp0000702

\section{Figures}




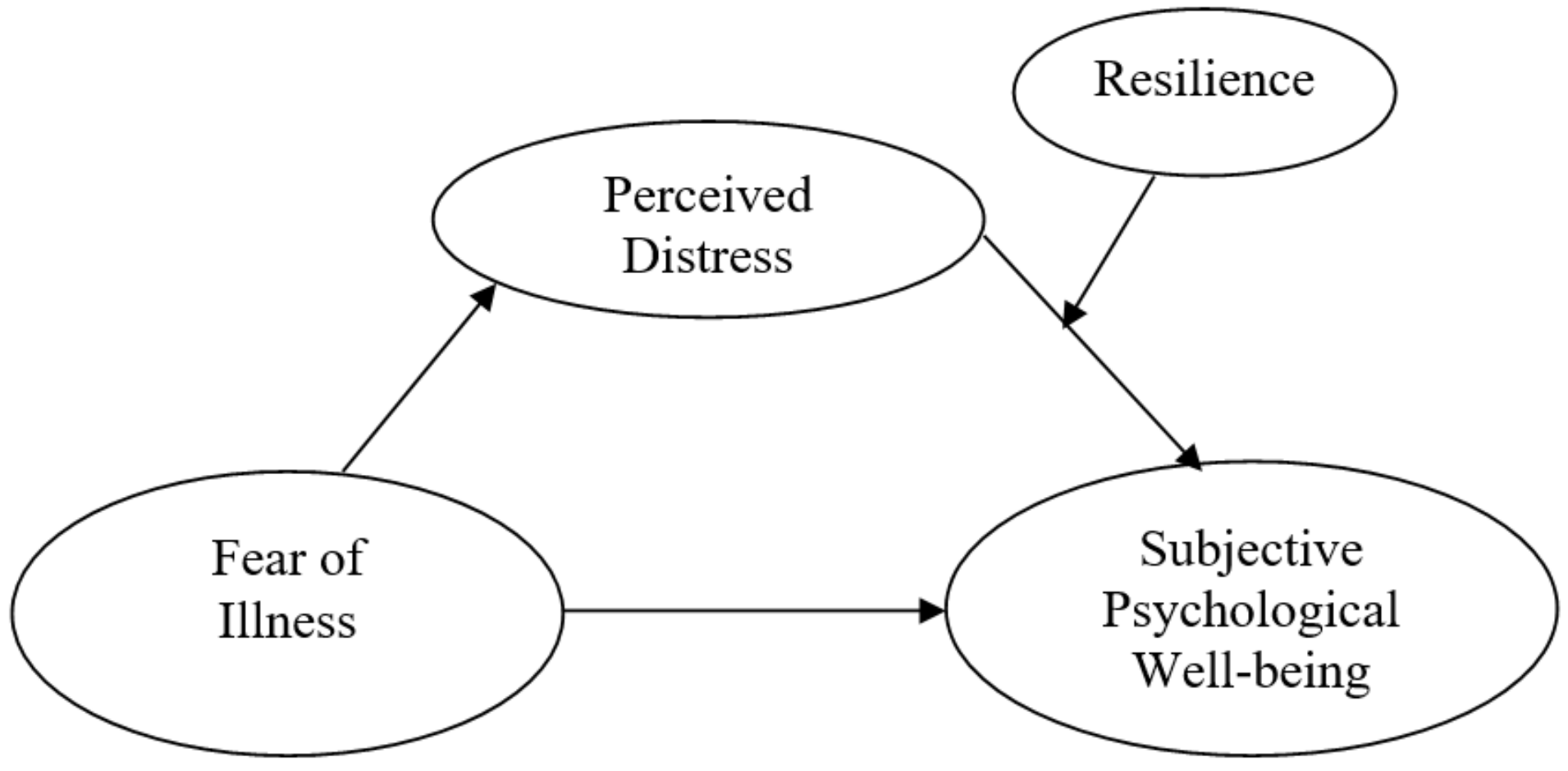

Figure 1

The Research Framework



Figure 2 
The Plot of Conditional Indirect Effect. Note: Green means high resilience, Red means medium resilience, and Blue means low resilience. 